\title{
PERSEPSI GURU ATAS SUPERVISI KEPEMIMPINAN KEPALA MADRASAH TERHADAP KINERJA GURU
}

\author{
Yunita Endra Megiati ${ }^{1}$, Noor Komari Pratiwi ${ }^{2}$ \\ Program Studi Teknik Informatika, Universitas Indraprasta PGRI ${ }^{1,2}$ \\ Email: yunitaendra@gmail.com
}

\begin{abstract}
Abstrak
Penelitian ini untuk mengetahui persepsi guru atas supervisi kepemimpinan kepala madrasah terhadap kinerja guru. Metode penelitian survei dengan sampel semua guru yang ada di MI Swasta Al Hikmah Bekasi, berjumlah dua puluh orang. Penelitian dilakukan pada tahun 2020. Data mengenai persepsi guru atas supervisi kemimpinan kepala madrasah terhadap kinerja guru diperoleh melalui kuesioner yang disusun oleh peneliti. Adapun hipotesis penelitian adalah persepsi guru atas supervisi kepemimpinan kepala madrasah berpengaruh secara signifikan terhadap kinerja guru. Hasil uji statistik menunjukkan nilai prob. Fhitung (sig.) < 0,05 yang berarti variabel persepsi guru atas supervisi kepemimpinan kepala madrasah $(X)$ secara signifikan berpengaruh terhadap variabel kinerja guru $(Y)$. Nilai koefisien korelasi ganda $(R)$ 0,862 berarti variabel persepsi guru atas supervisi kepemimpinan kepala madrasah $(X)$ dan variabel kinerja guru $(Y)$ memiliki hubungan yang sangat kuat. Selanjutnya, nilai koefisien determinasi $\left(R^{2}\right)$ 0,743 menunjukkan bahwa variabel persepsi guru atas supervisi kepemimpinan kepala madrasah $(X)$ berpengaruh sebesar $74,3 \%$ terhadap kinerja guru $(Y)$, sedangkan $25,7 \%$ dipengaruhi oleh variabel lain. Simpulannya adalah persepsi guru atas supervisi kepemimpinan kepala madrasah memengaruhi kinerja guru secara signifikan.
\end{abstract}

Kata Kunci : Supervisi, Kepemimpinan Kepala Madrasah, Kinerja Guru

\begin{abstract}
The purpose of this study is to discover teachers' perception of the leadership supervision of madrasah principals on teachers performance. The research method used was a survey with a sample of all teachers at MI Al Hikmah Bekasi, totaling twenty people. This study was conducted in 2020. Data on teacher perceptions towards the supervision from the head of madrasah on teacher performance were obtained through a questionnaire compiled by the researcher. The hypothesis of this study was that teachers' perceptions towards the supervision of madrasah principals have a significant effect on teachers performance. The statistical test results showed the prob value. F(sig.) $<0.05$, which meant that the teacher's perception of the leadership supervision of the head of madrasah $(X)$ had a significant effect on teacher performance $(Y)$. The value of the multiple correlation coefficient $(R)$ was 0.862 , indicating a very strong relationship between the variable teacher perceptions of the supervision of the head of madrasah $(X)$ and the teacher performance variable $(Y)$. Furthermore, the coefficient of determination $\left(R^{2}\right) 0.743$, indicating that the variable teacher perceptions of the supervision of the head of madrasah $(X)$ had an effect of $74.3 \%$ on teacher performance $(Y)$, while $25.7 \%$ was influenced by other variables. The conclusion is that teachers' perceptions of the leadership supervision of madrasah principals have a significant effect on teacher performance.
\end{abstract}

Key Words : Supervision, Leadership of Madrasah Principals, Teacher Performance

\section{PENDAHULUAN}

Pada era desentralisasi saat ini, sektor pendidikan dikelola secara otonomi oleh pemerintah daerah masing-masing, sehingga praktis pendidikan seharusnya bisa lebih baik dalam arti relevansinya, baik demi kepentingan daerah maupun nasional. Seyogianya, delegasi bidang pendidikan kepada pemerintahan daerah harus mampu memberikan kewenangan yang lebih proporsional bagi sekolah untuk menentukan kebijakan organisasi dan proses belajar-mengajar, manajemen guru, struktur dan perencanaan di tingkat sekolah, dan sumber pendanaan sekolah [1]. Agar otonomi pendidikan berhasil 
dengan baik, peran pemimpin sekolah/madrasah perlu diberdayakan. Kepala sekolah/madrasah harus mampu bertanggung jawab atas tugas dan wewenang yang dimiliki. Kepala sekolah/madrasah harus mampu sebagai manajer dan pemimpin. Sebagai manajer, kepala sekolah/madrasah dapat mengatur semua potensi yang dimiliki sekolah/madrasahnya agar berfungsi secara optimal. Hal ini akan berjalan jika kepala sekolah/madrasah melakukan fungsifungsi manajemen dengan baik.

Selain itu, sebagai pimpinan, kepala sekolah/madrasah perlu menerapkan kepemimpinan transformasional, agar setiap anggota sekolah/madrasah dapat berfungsi secara optimal [2]. Kepala sekolah harus mentransformasi peran setiap anggota sekolah/madrasah melalui bimbingan, pemberdayaan, dan anjuran agar tujuan lembaga tercapai secara optimal.

Pola kepemimpinan transformasional bisa menjadi pilihan bagi kepala sekolah/madrasah untuk memimpin dan mengembangkan sekolah/madrasah. Gaya kepemimpinan ini menekankan pentingnya penjelasan visi dan misi, komunikasi yang efektif, stimulasi intelektual, juga pemberian perhatian terhadap individu anggota sekolah/madrasah. Penerapan kepemimpinan transformasional diperlukan agar berbagai informasi terkini dapat ditransformasikan kepada seluruh anggota sekolah [3].

Selain itu, seorang pemimpin dalam lingkungan pendidikan juga dituntut untuk dapat berperan sebagai supervisor. Supervisi pendidikan adalah pembinaan untuk membantu guru dan pegawai sekolah dalam melaksanakan pekerjaan mereka secara efisien dan efektif. Supervisi kepala sekolah/madrasah diharapkan dapat membentuk sikap profesional. Sikap professional merupakan hal penting yang dapat mempengaruhi perilaku dan aktivitas guru dalam menjalankan tugas kesehariannya.

Selanjutnya, Luke dan Bernard mengatakan bahwa supervisi sesungguhnya dibutuhkan untuk meningkatkan skill atau kemampuan terkait dengan penyelenggaraan pembelajaran di kelas, kemampuan melakukan penilaian, kemampuan melakukan koordinasi dengan guru lain, kemampuan memahami hubungan berbagai aktivitas di sekolah, kemampuan membuat perencanaan fungsi sekolah, kemampuan mengambil putusan tentang sesuatu yang berkaitan dengan karir, kemampuan melakukan pengembangan layanan evaluasi, kemampuan menentukan intervensi kelas pembelajaran, dan terakhir adalah kemampuan menghandel sesuatu sesuai dengan konteksnya yang bervariasi [4].

Jelas terlihat bahwa sosok kepala sekolah/madrasah sebagai seorang pemimpin menduduki porsi yang sangat penting dalam meningkatkan kultur sekolah yang positif. Kultur yang dimaksud adalah pembudidayaan dalam ranah kognisi, afeksi, dan aksi-aksi motorik pada kehidupan sekolah/madrasah dan bermanfaat bagi proses pembelajaran dan peningkatan mutu hasil belajar siswa secara signifikan. Seperti hasil penelitian yang menyebutkan bahwa terdapat signifikansi pengaruh kepemimpinan kepala sekolah terhadap kinerja guru demi mewujudkan pendidikan yang berkualitas [5].

Guru sebagai agen pengetahuan senantiasa dituntut untuk meningkatkan kualitas peserta didik seutuhnya sehingga mampu memiliki daya saing yang tinggi dalam persaingan global. Kualitas hasil belajar di sekolah menuntut pengelolaan 
pembelajaran berkualitas tinggi. Secara keseluruhan, para pendidik, dalam hal ini guru, di dalam proses pendidikan memiliki tugas yang sangat penting. Keseluruhan tugas yang sangat berat itu akan terlaksana dengan baik jika didasari oleh minat dan motivasi kerja yang tinggi, kemampuan yang mumpuni, serta sikap yang profesional.

Kinerja guru merupakan parameter keberhasilan guru dalam menyelesaikan pekerjaannya untuk mencapai tujuan pendidikan. Selain itu, kinerja dari seorang guru ditunjukkan juga dari perilaku dalam bekerja. Adapun beberapa aspek penilaian kinerja guru, antara lain (1) merencanakan pembelajaran; dalam merencanakan pembelajaran, seorang guru harus menyusunnya semaksimal mungkin, (2) melaksanakan pembelajaran; adanya interaksi edukasi antara guru dan murid, (3) menilai hasil pembelajaran; guru menginterpretasikan hasil belajar siswa; (4) memberikan bimbingan dan pelatihan untuk peserta didik; kegiatan melatih dan membimbing peserta didik dapat dilakukan guru dalam kegiatan pembelajaran, kegiatan intrakulikuler dan juga ekstrakulikuler, dan (5) melaksanakan tugas tambahan, seperti menjadi kepala perpustakaan atau labiratorium [6]. "Persepsi adalah tanggapan (penerimaan) langsung dari sesuatu; serapan; proses seseorang mengetahui beberapa hal melalui pancaindranya" [7]. Dalam penelitian ini, yang dimaksud dengan persepsi guru adalah tanggapan dari diri seorang guru yang diperoleh melalui proses mengetahui atau mengenali objek dan kejadian objektif yang ada di lingkungannya dengan bantuan indranya berkaitan dengan supervisi kepemimpinan kepala madrasah.

Beberapa indikator untuk mengukur persepsi guru atas supervisi kepemimpinan kepala madrasah dituliskan dalam Tabel berikut ini.

Tabel 1. Indikator Supervisi Kepemimpinan Kepala Madrasah

\begin{tabular}{clc}
\hline No & \multicolumn{1}{c}{ Indikator } & Butir \\
\hline 1. & $\begin{array}{l}\text { membuat perencanaan untuk } \\
\text { kegiatan pembelajaran }\end{array}$ & $1-5$ \\
2. & memberikan motivasi & $6-10$ \\
3. & memberikan pelatihan & $11-15$ \\
4. & $\begin{array}{l}\text { melaksanakan kegiatan } \\
\text { pengontrolan }\end{array}$ & $16-20$ \\
5. & $\begin{array}{l}\text { menjalankan fungsi sebagai } \\
\text { pimpinan }\end{array}$ & $21-25$ \\
\hline & & Sumber: [4]
\end{tabular}

Dari hasil supervisi tersebut, dapat diketahui tingkat kompetensi guru, baik kelemahan maupun keunggulannya. Selanjutnya, solusi dan pembinaan tertentu dapat dilakukan agar guru dapat mengembangkan potensinya dalam pelaksanaan pembelajaran [4].

Tujuan penelitian ini untuk mengetahui tingkat hubungan antara variabel persepsi guru atas supervisi kepemimpinan kepala madrasah dan kinerja guru. Hipotesis penelitian ini adalah persepsi guru atas supervisi kepemimpinan kepala madrasah berpengaruh terhadap kinerja guru secara signifikan. Hasil penelitian ini bisa menjadi bahan pertimbangan dan masukan bagi Kepala MI Swasta Al Hikmah dalam pengambilan keputusan untuk menetapkan kebijakan sekolah agar kinerja guru semakin meningkat demi pendidikan yang berkualitas.

\section{METODE}

Peneliti membatasi masalah yang diteliti mengenai variabel persepsi guru atas supervisi kepemimpinan kepala madrasah terhadap variabel kinerja guru. Penelitian dilakukan pada tahun 2020. Populasi penelitian adalah guru di MI Swasta yang ada di Kampung Kebantenan, Kecamatan Jati Asih, Kota Bekasi. Populasi terjangkaunya adalah guru di MI Swasta Al Hikmah yang ada di Kampung 
Kebantenan, Kecamatan Jati Asih, Kota Bekasi dan sampel penelitian ini adalah seluruh guru MI Swasta Al Hikmah berjumlah 20 orang. Penelitian menggunakan metode survei deskriptif. "Survei adalah pengamatan atau penyelelidikan yang kritis untuk mendapatkan keterangan yang terang dan baik terhadap suatu persoalan tertentu dan di dalam suatu daerah tertentu" [8]. Metode survei tidak melakukan perubahan pada variabel tertentu, meneliti apa adanya, dan tidak ada variabel yang dikontrol. Selanjutnya, dalam penelitian survei deskriptif, penelitian terbatas pada usaha untuk mengungkapkan suatu keadaan yang apa adanya sehingga bersifat sekadar untuk mengungkapkan fakta.

Teknik pengumpulan data penelitian ini menggunakan kuesioner. Kemudian, teknik analisis penelitian dengan analisis korelasional. Analisis korelasional adalah analisis atau penelitian yang tujuannya mendeteksi keeratan hubungan variasi pada suatu faktor berkaitan dengan variasi pada satu atau lebih faktor lain berdasarkan koefisien korelasi [9]. "Penelitian korelasi berkaitan dengan pengumpulan data untuk menentukan ada atau tidaknya hubungan antara dua variabel atau lebih dan seberapakah tingkat hubungannya". Lebih lanjut dijelaskan, tingkat hubungan antara variabel dinyatakan sebagai suatu koefisien korelasi [10]. Variabel-variabel yang diteliti adalah variabel persepsi guru atas supervisi kepemimpinan kepala madrasah yang merupakan variabel bebas $(X)$ dan variabel kinerja guru yang merupakan varibel terikat $(Y)$.

\section{HASIL DAN PEMBAHASAN}

Deskripsi Data Persepsi Guru atas Supervisi Kepemimpinan Kepala Madrasah

Deskripsi data persepsi guru atas supervisi kepemimpinan kepala madrasah ditunjukkan dalam Tabel berikut ini.
Tabel 2. Deskripsi Data Persepsi Guru atas Supervisi Kepemimpinan Kepala Madrasah

\begin{tabular}{lrr}
\hline$N$ & Valid & 20 \\
& Missing & 0 \\
Mean & & 90,8 \\
Median & 89 \\
Mode & 85 \\
Std. Deviation & 8,829 \\
Variance & 77,958 \\
Kurtosis & $-0,965$ \\
Std. Error of Kurtosis & 0,992 \\
Range & 28 \\
Minimum & 79 \\
Maximum & 107 \\
Sum & 1816 \\
\hline
\end{tabular}

Tabel 2 menunjukkan data persepsi guru atas supervisi kepemimpinan kepala madrasah berdasarkan beberapa indikator yang ada pada Tabel 1 sebelumnya. Diperoleh nilai mean 90,8 dan median 89.

\section{Deskripsi Data Kinerja Guru}

Deskripsi data kinerja guru ditunjukkan dalam Tabel di bawah ini.

\section{Tabel 3. Deskripsi Data Kinerja Guru}

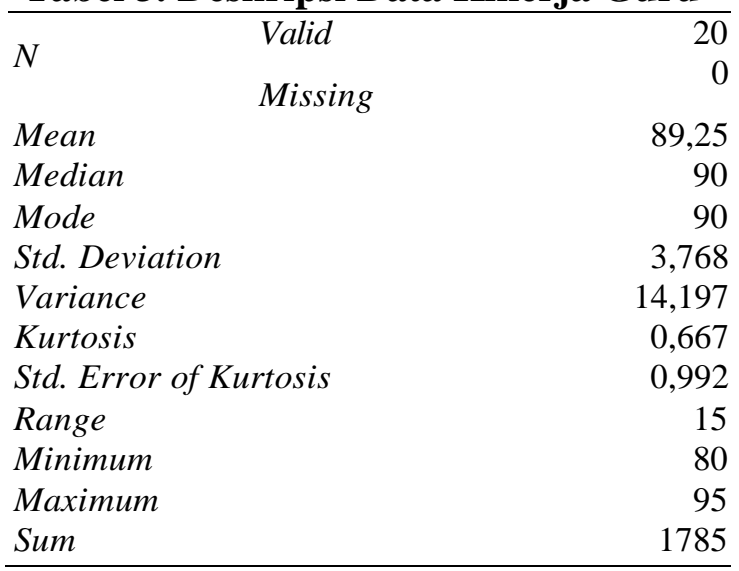

Tabel 3 di atas menunjukkan data kinerja guru yang dinilai berdasarkan perencanaan dan pelaksanaan pembelajaran, penilaian hasil pembelajaran, bimbingan dan pelatihan terhadap peserta didik, serta tugas tambahan. Diperoleh nilai mean 89,25 dan median 90. 


\section{Uji Linearitas}

Tabel 4 di bawah ini menunjukkan hasil uji linearitas, yaitu nilai Deviation from Linearity dengan nilai Sig. $=0,090>0,05$ yang berarti variabel persepsi guru atas supervisi kepemimpinan kepala madrasah
$(X)$ dan variabel kinerja guru $(Y)$ mempunyai hubungan linear. Hasil uji linearitas antara variabel persepsi guru atas supervisi kepemimpinan kepala madrasah $(X)$ dan variabel kinerja guru $(Y)$ secara rinci dapat dilihat pada Tabel berikut.

Tabel 4. Uji Linearitas

\begin{tabular}{|c|c|c|c|c|c|}
\hline & $\begin{array}{l}\text { Sumof } \\
\text { Squares }\end{array}$ & $d f$ & $\begin{array}{l}\text { Mean } \\
\text { Square }\end{array}$ & $F$ & Sig. \\
\hline Kinerja Guru * Between (Combined) & 257,000 & 12 & 21,417 & 11,758 & ,002 \\
\hline $\begin{array}{lr}\text { Persepsi } & \text { Groups Linearity } \\
\text { atas } & \text { Deviation }\end{array}$ & 200,530 & 1 & 200,530 & 110,095 &, 000 \\
\hline $\begin{array}{ll}\text { Supervisi } & \text { from } \\
\text { Kepemimpinan } & \text { Linearity }\end{array}$ & 56,470 & 11 & 5,134 & 2,818 & ,090 \\
\hline $\begin{array}{l}\text { Within Groups } \\
\text { Total }\end{array}$ & $\begin{array}{r}12,750 \\
269,750 \\
\end{array}$ & $\begin{array}{r}7 \\
19 \\
\end{array}$ & 1,821 & & \\
\hline
\end{tabular}

\section{Uji Normalitas}

Persyaratan regresi yang baik jika data penelitian mengikuti distribusi normal.
Hasil uji normalitas dapat dilihat pada Tabel 5 berikut ini.

Tabel 5. Uji Normalitas

One-Sample Kolmogorov-Smirnov Test

\begin{tabular}{|c|c|}
\hline & $\begin{array}{c}\text { Unstandardized } \\
\text { Residual }\end{array}$ \\
\hline $\bar{N}$ & 20 \\
\hline Normal Parameters ${ }^{a, b}$ Mean & ,0000000 \\
\hline Std. Deviation & 1,90870615 \\
\hline Most Extreme Differences & , 192 \\
\hline Positive & , 130 \\
\hline Negative &,- 192 \\
\hline Kolmogorov-Smirnov $Z$ &, 861 \\
\hline Asymp. Sig. (2-tailed) & 449 \\
\hline
\end{tabular}

Tabel 5 menunjukkan distribusi residual pada analisis regresi ini berdistribusi normal. Dapat dilihat dari nilai Sig. $=$ $0,449>0,05$ yang berarti persyaratan analisis regresi terpenuhi.

\section{Uji Hipotesis Penelitian}

Hasil analisis regresi linear sederhana dengan satu variabel bebas $(X)$ terhadap variabel terikat $(Y)$ dapat dilihat pada tabel di bawah ini.

Tabel 6. Hasil Perhitungan Pengujian Koefisien Korelasi Sederhana

Variabel $X$ terhadap Variabel $Y$ Model Summary

\begin{tabular}{ccccc}
\hline Model & $R$ & $R$ Square & $\begin{array}{c}\text { Adjusted } R \\
\text { Square }\end{array}$ & $\begin{array}{c}\text { Std. Error of the } \\
\text { Estimate }\end{array}$ \\
\hline 1 &, $862^{\mathrm{a}}$ &, 743 &, 729 & 1,961 \\
\hline
\end{tabular}

a. Predictors: (Constant), Persepsi Guru atas Supervisi Kepemimpinan Kepala Madrasah 
Tabel 6 menunjukkan besarnya nilai koefisien korelasi $(R)$ adalah 0,862 . Nilai ini menunjukkan keeratan hubungan yang sangat kuat antara variabel persepsi guru atas supervisi kepemimpinan kepala madrasah $(X)$ dan variabel kinerja guru $(Y)$.
Selanjutnya, nilai koefisien determinasi atau $R$ Square $\left(R^{2}\right)$ adalah 0,743 menunjukkan bahwa variabel persepsi guru atas supervisi kepemimpinan kepala madrasah $(X)$ memberikan pengaruh sebesar 74,3\% terhadap kinerja guru $(Y)$.

\section{Tabel 7. Hasil Perhitungan Pengujian Signifikansi Koefisien Sederhana Variabel $X$ terhadap Variabel $Y$

\begin{tabular}{llccccc}
\multicolumn{8}{c}{ ANOVA $^{\boldsymbol{b}}$} \\
\hline \multirow{4}{*}{ Model } & Sumof & $d f$ & Mean & $F$ & Sig. \\
& Squares & & Square & & \\
\hline \multirow{3}{*}{1} & Regression & 200,530 & 1 & 200,530 & 52,146 &, 000 \\
& Residual & 69,220 & 18 & 3,846 & &
\end{tabular}

Total 269,750 19

a. Predictors: (Constant), Persepsi Guru atas Supervisi Kepemimpinan Kepala Madrasah

b. Dependent Variable: Kinerja Guru

Tabel 7 menunjukkan nilai Sig. $<0,05$ yang berarti secara signifikan persepsi guru atas supervisi kepemimpinan kepala madrasah $(X)$ berpengaruh terhadap terhadap kinerja guru $(Y)$.

Tabel 8. Hasil Perhitungan Persamaan Regresi Sederhana Variabel $X$ terhadap Variabel $Y$

Coefficients $^{a}$

\begin{tabular}{|c|c|c|c|c|c|}
\hline \multirow{2}{*}{ Model } & \multicolumn{2}{|c|}{$\begin{array}{c}\text { Unstandardized } \\
\text { Coefficients }\end{array}$} & \multirow{2}{*}{$\begin{array}{r}\begin{array}{r}\text { Standardized } \\
\text { Coefficients }\end{array} \\
\text { Beta }\end{array}$} & \multirow[t]{2}{*}{$t$} & \multirow{2}{*}{ Sig. } \\
\hline & $B$ & Std. Error & & & \\
\hline (Constant) & 55,841 & 4,647 & & 12,016 & , 000 \\
\hline \multirow{2}{*}{$\begin{array}{l}1 \text { Persepsi Guru } \\
\text { Supervisi Kepemimpinan } \\
\text { Kepala Madrasah }\end{array}$} & & & & & \\
\hline & ,368 & ,051 & ,862 & 7,221 & , 000 \\
\hline
\end{tabular}

a. Dependent Variable: Kinerja Guru

Berdasarkan Tabel 8, diperoleh nilai signifikansi sebesar 0,000 yang artinya nilai tersebut lebih kecil dari 0,05. Jadi, hipotesis yang berbunyi persepsi guru atas supervisi kepemimpinan kepala madrasah berpengaruh terhadap kinerja guru secara signifikan diterima. Dari tabel 8 diketahui persamaan regresi $Y=55,841+0,368 X$. Persamaan tersebut menjelaskan jika tanggapan atau persepsi guru atas supervisi kepemimpinan kepala madrasah bernilai sangat rendah $(X=0)$, guru memiliki nilai kinerja sebesar 55,841 dan apabila tanggapan atau persepsi guru atas supervisi kepemimpinan kepala madrasah bernilai 1 $(X=1)$, nilai kinerja guru akan bertambah sebesar 0,368. Berarti, dapat disimpulkan bahwa semakin baik tanggapan atau persepsi guru atas supervisi kepemimpinan kepala madrasah, akan semakin baik kinerja guru. Hasil penelitian ini sama dengan penelitian yang menyebutkan bahwa supervisi kepemimpinan kepala sekolah berpengaruh secara positif dan signifikan terhadap kinerja guru [11].

Hal ini juga sesuai dengan hasil penelitian lain yang salah satu simpulan dalam penelitiannya adalah terdapat pengaruh langsung positif dan signifikan kepemimpinan kepala sekolah terhadap kinerja guru [12]. Selanjutnya, dijelaskan 
bahwa peran kepala sekolah sebagai pemimpin adalah membina para anggota masyarakat sekolah dalam melakukan pekerjaan mereka secara efektif. Kepemimpinan kepala sekolah/madrasah dilihat dari cara memperlakukan sumber daya manusia dengan bijaksana. Hal ini berdampak pada hasil kerja yang didapatkan oleh guru atau pendidik yang ada di dalam satuan pendidikan yang dipimpinnya. Oleh karena itu, bisa diasumsikan bahwa semakin baik kepemimpinan kepala sekolah, akan semakin baik kinerja guru [12].

Pendidikan merupakan sistem kerja yang saling terkait antara komponen yang satu dan lainnya. Bila selama ini guru selalu menjadi sorotan sekaligus ujung tombak pelaksanaan pendidikan di berbagai jenjang pendidikan, sebenarnya ada komponen lain yang harus diberdayakan dalam aplikasi pendidikan yaitu peran kepala sekolah. Hasil guru dalam mengabdikan dirinya sebagai pengajar dan pendidik bergantung pada kondisi lingkungan sekaligus figur pemimpin sekolah [2].

\section{SIMPULAN}

Dari hasil penelitian yang dilakukan pada tahun 2020 terhadap 20 guru MI Al Hikmah di Kampung Kebantenan, Kecamatan Jati Asih, Kota Bekasi, ditarik simpulan bahwa persepsi guru atas supervisi kepemimpinan kepala madrasah berpengaruh terhadap kinerja guru secara signifikan. Perolehan persamaan regresi $Y=$ $55,841+0,368 X$ menunjukkan semakin baik persepsi atau tanggapan guru atas supervisi kepemimpinan kepala madrasah, semakin baik pula kinerja guru.

\section{DAFTAR PUSTAKA}

[1] S. Subijanto, "Prinsip-Prinsip dan Efektivitas Desentralisasi Pendidikan dalam Rangka Meningkatkan Mutu dan Relevansi Pendidikan," $J$.
Pendidik. dan Kebud., pp. 532-549, 2010, doi: 10.24832/jpnk.v16i5.484.

[2] Iskandar dan Mukhtar. Orientasi Baru Supervisi Pendidikan. Jakarta: Reverensi, 2013.

[3] S. Danim dan Suparno. Manajemen dan

Kepemimpinan

Transformasional

Kekepalasekolahan: Visi dan Sukses

Era Teknologi, Situasi Krisis, dan Internasionalisasi Pendidikan. Jakarta: PT Rineka Cipta, 2009.

[4] S. Hidayat. Profesi Kependidikan; Teori dan Praktik di Era Otonomi. Tangerang: Pustaka Mandiri, 2016.

[5] M. Kosim, "Pengaruh Kepemimpinan Kepala Sekolah terhadap Kinerja Guru untuk Mewujudkan Mutu Pembelajaran," Khazanah Akad., vol. 1, pp. 30-38, 2017, [Online]. Available: https://journal.uniga.ac.id/index.php/ K/article/view/167.

[6] Barnawi dan M. Arifin. Kinerja Guru Profesional; Instrumen Pembinaan, Peningkatan, dan Penilaian. Yogyakarta: Ar-ruzz Media, 2012.

[7] Badan Pengembangan dan Pembinaan Bahasa. "Kamus Besar Bahasa Indonesia Daring," 2016. https://kbbi.kemdikbud.go.id/.

[8] S Margono. Metodologi Penelitian Pendidikan. Jakarta: Rineka Cipta, 2013.

[9] Mahmud. Metode Penelitian Pendidikan. Bandung: Pustaka Setia, 2011.

[10] Sudaryono. Metodologi Penelitian. Depok: Raja Wali Press, 2017.

[11] Hardono, Haryono, dan A. Yusuf, "Kepemimpinan Kepala Sekolah, Supervisi Akademik, dan Motivasi Kerja dalam Meningkatkan Kinerja Guru," Educ. Manag., vol. 6, no. 1, pp. 26-33, 2017.

[12] R. Astuti dan M. I. Dacholfany, "Pengaruh Supervisi Pengawas 
Sekolah dan Kepemimpinan Kepala Sekolah terhadap Kinerja Guru SMP di Kota Metro Lampung," J. Lentera
Pendidik. Pus. Penelit. Lppm Um Metro, 2016. 